\title{
Infrastructure is not enough: Interactions between the environment, socioeconomic disadvantage, and cycling participation in England
}

\author{
Eugeni Vidal Tortosa \\ Robin Lovelace \\ Eva Heinen \\ University of Leeds \\ University of Leeds \\ University of Leeds

\section{Richard P Mann} \\ University of Leeds and The Alan Turing Institute
}

\begin{abstract}
Cycling can be particularly beneficial for socioeconomically disadvantaged populations for two main reasons. First, cycling enables access to opportunities that may be unaffordable by other modes. Second, cycling increases physical activity levels and, consequently, improves health. In this context, we analyze the extent to which socioeconomic disadvantage impacts cycling participation and cycling duration for both leisure and utility cycling. Then, we examine whether socioeconomic inequalities in cycling participation can be explained by the environment in which disadvantaged populations live. The study population includes 167,178 individuals, residing in 2,931 areas, and 326 Local Authorities. Data on individual factors were drawn from the Active Lives Survey and data on environmental factors from several sources. Descriptive statistics and multilevel regression models were estimated. We found that the likelihood of cycling is lower among people living in deprived areas than among people living in non-deprived areas. This difference is significant for leisure, but also for utility cycling when controlling for individual and environmental factors. However, cyclists living in deprived areas are more likely to cycle longer per week than cyclists living in non-deprived areas, particularly for utility cycling. We also found that cycling infrastructure and greater levels of cyclability are higher in deprived areas than in non-deprived areas. This suggests that infrastructure and cyclability are not enough to increase cycling levels among disadvantaged populations. Further research on other barriers to cycling among disadvantaged populations is required.
\end{abstract}

Article History:

Received: April 18, 2020

Accepted: Decem-

ber 11,2020

Available online: July

6,2021

Keywords: utility cycling, leisure cycling, transport equity, physical activity, environmental justice

Copyright 2021 Eugeni Vidal Tortosa; Robin Lovelace; Eva Heinen; Richard P Mann.

doi: $10.5198 /$ jtlu.2021.1781

ISSN: 1938-7849| Licensed under the Creative Commons Attribution - NonCommercial License 4.0.

The Journal of Transport and Land Use is the official journal of the World Society for Transport and Land Use (WSTLUR) and is published and sponsored by the University of Minnesota Center for Transportation Studies. 


\section{Introduction}

The benefits of cycling are widely recognized. Cycling is healthy, affordable, efficient, improves environmental quality, traffic congestion, and avoids climate change (Garrard et al. 2012; Heinen et al. 2010; Oja et al. 2011; Pucher et al. 2010). For this reason, governments at different administrative levels are increasingly implementing policies to encourage people of all ages and backgrounds to cycle.

One group that has much to gain from cycling promotion is the socioeconomically disadvantaged populations (Lee et al. 2012). First, because cycling can allow them to access opportunities such as better work, training or leisure, that by other modes of transport they may not afford. Second, because it can help these populations to increase their physical activity levels and, consequently, improve their health. Disadvantaged populations tend to be less physically active than non-disadvantaged populations (Droomers 2001; Giles-Corti 2002; Lindström et al. 2001), which has been suggested to explain, at least in part, their poorer health condition and life expectancy (Lynch et al. 1996).

The relationship between socioeconomic disadvantage and cycling is ambiguous. Most authors agree that cycling for sport and recreation (leisure cycling) is more common among middle- and highincome populations than among low-income populations (e.g., (Bandeira et al. 2017; Heesch et al. 2015; Kamphuis et al. 2008). However, the extent to which different socioeconomic groups use cycling for transport (utility cycling) seems to be context-dependent. Whereas in developing countries utility cycling is mainly used by low-income groups (Brussel and Zuidgeest 2012; Vasconcellos 2001), in developed countries this is not always the case. In Northern Europe, cycling levels are relatively constant between different socioeconomic groups (Pucher and Buehler 2008). However, in developed countries where cycling is rare findings are mixed. In the US and Canada, there is evidence that cycling for transport is more common among low-income populations than among higher-income groups (e.g., (Plaut 2005; Pucher et al. 1999; Schwanen and Mokhtarian 2005; Winters et al. 2010). Also in the US, some authors found no association between socioeconomic status and utility cycling (e.g., (Dill and Carr 2003; Handy and Xing 2011). In the UK and Australia, by contrast, research has found higher levels of utility cycling among middle- and high-income groups (e.g., (Green et al. 2010; Parkin et al. 2008; Sahlqvist and Heesch 2012; Steinbach et al. 2011).

Research shows that environmental factors such as cycle-friendly infrastructure, traffic volume, density, and hilliness influence cycling levels (Fraser and Lock 2011; Heinen et al. 2010; Wang et al. 2016; Winters et al. 2010). Therefore, the environment in which specific groups live could explain, at least in part, inequalities in cycling participation. It is in this context in which the research area 'cycling equity' has recently emerged. In the US, for example, a recent study based on data from 22 large cities found that access to cycling infrastructure was lower in groups with particular types of disadvantage (lower education, higher Hispanic populations, lower composite SES), but not in groups with other types of disadvantage (higher black populations, lower-income, higher poverty) (Braun et al. 2019). In most Canadian cities, low-income populations were found to have better access to cycling facilities than wealthier populations (Fuller and Winters 2017; Winters et al. 2018). By contrast, in South America, the result of two studies found that the poor areas were under-served (Teunissen et al. 2015; Tucker and Manaugh 2018). Finally, in Melbourne (Australia), the cycling network was found generally equitably distributed, although more off-road infrastructure, i.e., safer cycling routes, was found in wealthier areas (Pistoll and Goodman 2014).

In recent years, there has been a rise in walking and cycling investment in the UK (DfT 2017). Some of these projects aim to enable disadvantaged groups to cycle. For example, the Bradford Leeds Cycle Superhighway (WYCA 2019) was designed to offer one of the most disadvantaged communities in West Yorkshire (UK) a cheap and healthy means of transportation between the cities of Bradford and Leeds. However, except for a couple of socio-spatial studies on the provision of bicycle-sharing systems (Clark and Curl 2016; Goodman and Cheshire 2014), no study in England has explored to date the influence that the level of deprivation in which population lives might have on cycling. The level of cycle-friendliness of deprived areas, or to what extent the environmental improvement of these 
areas could help increase cycling participation among the most disadvantaged groups have also not been considered.

This paper fills these gaps by addressing two aims. First, it analyzes the extent to which socioeconomic disadvantage in England impacts cycling participation and cycling duration for both leisure cycling and utility cycling. Second, it examines whether socioeconomic inequalities in cycling participation could be explained by the environment in which disadvantaged populations live. The findings of the study are intended to inform policies to facilitate cycling among socioeconomically disadvantaged populations. This will allow vulnerable groups to gain accessibility and health, and get more people cycling, which in the long run will benefit us all.

\section{Data and Methods}

\subsection{Data}

To understand the relationships between the environment, socioeconomic disadvantage, and cycling participation a combination of 'individual' and 'area' level sources was needed. The individuallevel data were extracted from the Active Lives Adult Survey (ALS). The ALS is a biannual survey that contains frequencies and duration of physical activity, including walking and cycling for travel, of adults aged 16+ in England. Its responses are collected using Computer-assisted web interviewing (CAWI) online questionnaires and paper self-completion questionnaires, and its sampling is clustered at the Local Authority (LA) level with a minimum of 500 interviews in most LAs (303 of 326), which allows performing analysis up to this geographical level (Ipsos MORI 2019). For this study, the ALS for the period mid-November 2017 to mid- November 2018 was used.

The area-level data were obtained from the Cycling Infrastructure Prioritisation Toolkit (University of Leeds 2019), the CycleStreets website (Cycle Streets 2020), the Office for National Statistics (ONS 2019), and the open-source online system for sustainable transport planning Propensity for Cycle Tool (Lovelace et al. 2017).

\subsection{Variables}

\subsubsection{Response variables}

Respondents of the ALS were asked for the frequency (number of times in the last 4 weeks) and the duration (minutes per week) of their cycling activity. Based on this, we used two response variables:

1. a binary variable 'cycling participation' expressing whether individuals cycled or did not cycle in the last 4 weeks, and

2. a continuous variable 'cycling duration' specifying the weekly minutes they travelled by bicycle. Each of these variables was calculated separately for total cycling, leisure cycling, and utility cycling.

\subsubsection{Explanatory variables}

A range of individual and area-level factors previously found to be associated with cycling (Fraser and Lock 2011; Heinen et al. 2010; Wang et al. 2016; Winters et al. 2010) were selected as explanatory variables (see Table 1). Seven individual-level factors were extracted from the ALS: 'Gender' (male/female), 'Age' (16-34, 35-54, 55-74, 75+), 'Ethnicity' (white/non-white), 'Education' (low, medium, high)1', 'Occupation' (NS SEC 1-2 Higher social groups, NS SEC 3-5 Middle social groups, NS SEC 6-8 Lower social groups, and NS SEC 9 Students and other) ${ }^{2}$, 'Type of area' (urban/rural),

\footnotetext{
${ }^{1}$ Education was categorized as 'low' (levels 1 or 2 and equivalents (GCSE-level) or below, or 'No qualifications', or 'Another type of qualification'), 'medium' (level 3 and equivalents), or 'high' (level 4 or above).

${ }^{2}$ Occupation was categorized as 'NS SEC 1-2 Higher social groups' (Managerial, administrative and professional occupations), 'NS SEC 3-5 Middle social groups' (Intermediate occupations, small employers and own account workers, and Lower supervisory and tech occupations), 'NS SEC 6-8 Lower social groups' (Semi-routine, routine occupations, and Long term unemployed or never worked), or 'NS SEC 9 Students and other' (Full-time student and unclassified).
} 
and 'Level of deprivation' of the area where respondents resided (Q1 most, Q2, Q3, Q4, Q5 least). Level of deprivation was used as a proxy for socioeconomic disadvantage and refers to the Index of Multiple Deprivation 2015 (IMD) of the small areas (Lower-layer Super Output Areas (LSOA)) of England. This indicator is based on seven different domains of deprivation: Income Deprivation, Employment Deprivation, Education, Skills and Training Deprivation, Health Deprivation and Disability, Crime, Barriers to Housing and Services, and Living Environment Deprivation (DfCLG 2015).

Five environmental factors were included from several sources. 'Cycle tracks (off-road)' and 'Cycle lanes (on-road)' were collected from the Cycling Infrastructure Prioritisation Toolkit (University of Leeds 2019) ${ }^{3}$, and 'Quietness' (\% score per level of stress of routes in each area) from the CycleStreets website (Cycle Streets 2020). For these three variables, a $1 \mathrm{~km}$ buffer per area was created to avoid over or under-representation in the smallest areas. 'Density' (Population $/ \mathrm{km} 2$ ) was provided from the Office for National Statistics (ONS 2019). Finally, 'Hilliness' (average fast route gradient (\%) of commute trips in zone with fast route distance $<10 \mathrm{~km}$ at the English Middle-layer Super Output Areas (MSOA) level) was taken from the Propensity for Cycle Tool (Lovelace et al. 2017).

\subsection{Data preparation}

Respondents with missing data for 'Ethnicity,' 'Education,' 'Gender,' and 'Age' were excluded ( $\mathrm{n}=$ 12,569), which reduced the sample size to $n=167,178$ (Table 1). To avoid the presence of extreme high values in the response variable 'cycling duration', a cut-off of 3,000 minutes/week ( 50 hours/week) was used. For those individuals who exceed this value $(n=42)$, the mean duration of those who cycled at least once in the last 4 weeks per type of cycling was imputed. Since we did not have access to the individual identifiers of the small areas (LSOA) in the ALS, which is the area-level at which the Index of Multiple Deprivation (IMD) was collected, to merge the individual and the area datasets at a level that could take into account the IMD, first, we had to aggregate the LSOAs dataset by IMD decile and Local Authority (LA). With this aggregate we had the area dataset at the IMD decile LA-level, that is, with a maximum of 10 rows per LA (depending on the IMD deciles that each LA had). Then, we joined the individual and area dataset by the common fields 'IMD decile' and 'LA'. The result was a dataset with two levels: the individual-level with 167,178 individuals and 13 variables ( 3 outcomes for cycling participation, 3 outcomes for cycling duration, and 7 explanatory variables), and the IMD decile LA-level with 2,931 areas and (the remaining explanatory) 5 variables.

\subsection{Statistical methods}

First, we carried out descriptive statistics. For this, two area-level response variables per type of cycling were calculated: the 'proportion cycling participation' by adding per IMD decile LA area the number of individuals that cycled in the last 4 weeks and dividing it by the total individuals of each area, and the 'average cycling duration' by taking the mean of cycling duration of those who cycled in the last 4 weeks per each IMD decile LA area. With these variables, first, we mapped the proportions of cycling per type of cycling; then, we created several boxplots. A boxplot of proportions of cycling participation by quintile level of deprivation, a boxplot of average cycling duration by quintile level of deprivation, and a boxplot of the density of cycling infrastructure (cycle tracks and cycle lanes) by quintile level of deprivation. Finally, we draw a bar graph with the area-level response variable proportion of cycling participation per type of cycling and all the different environmental variables standardized by quintile level of deprivation. To do this, we took the values of each variable, subtracting its mean and dividing the differences by the standard deviation.

Second, considering the hierarchical structure of the data (individuals, IMD decile LA areas, and LAs) and the distribution of the two response variables, we estimated odds ratios (ORs) to explain cycling participation and cycling duration for the explanatory variables using two multilevel regression

\footnotetext{
${ }^{3}$ The data used in the Cycling Infrastructure Prioritisation Toolkit was extracted from the Open Street Map (OSM) mid 2017.
} 
Table 1: Descriptive statistics.

\begin{tabular}{ll}
\hline Variables & Statistics \\
\hline Individual factors & \\
No. of individuals (n) & 167178 \\
Gender & \\
Male & $73904(44.2 \%)$ \\
Female & $93274(55.8 \%)$ \\
Age & \\
16-34 & $31785(19.0 \%)$ \\
35-54 & $55293(33.1 \%)$ \\
55-74 & $64352(38.5 \%)$ \\
75+ & $15748(9.4 \%)$ \\
Ethnicity & \\
White & $154399(92.4 \%)$ \\
Non-white & $12779(7.6 \%)$ \\
Education & \\
High & $85098(50.9 \%)$ \\
Medium & $25258(15.1 \%)$ \\
Low & $56822(34.0 \%)$ \\
Occupation & \\
NS SEC 1-2: Higher social groups & $84636(50.6 \%)$ \\
NS SEC 3-5: Middle social groups & $39353(23.5 \%)$ \\
NS SEC 6-8: Lower social groups & $18500(11.1 \%)$ \\
NS SEC 9: Students and others & $8941(5.3 \%)$ \\
Missing & $15748(9.4 \%)$ \\
Type of area & \\
Urban & $128530(76.9 \%)$ \\
Rural & $38648(23.1 \%)$ \\
Level of deprivation & \\
Q1 (most) & $32163(19.2 \%)$ \\
Q2 & $33189(19.9 \%)$ \\
Q3 & $33786(20.2 \%)$ \\
Q4 & $33748(20.2 \%)$ \\
Q5 (least) & $34292(20.5 \%)$ \\
Environmental factors & \\
No. of areas (n) & 2931 \\
Cycle tracks (off-road) $(\mathrm{km} / \mathrm{km}$ ^2), mean $(\mathrm{SD})$ \\
Cycle lanes (on-road) $\left(\mathrm{km} / \mathrm{km}{ }^{\wedge} 2\right)$, mean $(\mathrm{SD})$ \\
Quietness (\%), mean $(\mathrm{SD})$ & $3.7(6.5)$ \\
Density (population/km^2), mean (SD) & $71.9(1.6)$ \\
Hilliness (\%), mean (SD) & $2583.7(3141.7)$ \\
\hline & $1.9(0.9)$ \\
\hline
\end{tabular}

models: 1) a multilevel logistic regression to predict cycling participation (binary variable), where 'participating' individuals were those who cycled at least once in the last 4 weeks, and for those individuals who cycled at least once in the last 4 weeks 2 ) a multilevel gamma regression to predict weekly cycling duration (continuous variable). We conducted this analysis per each type of cycling: total cycling, leisure cycling, and utility cycling. Figure 1 illustrates the conceptual models.

First, we adjusted the models only for the 'individual' fixed effects; then, we adjusted them for both the 'individual' and 'environmental' fixed effects. Multicollinearity was tested to avoid multiple factors correlated to each other. For this, multiple logistic regression models were fitted and the Variance Inflation Factor (VIF) among factors measured. The VIF score of an independent variable represents how well the variable is explained by other independent variables. A VIF score over 5 indicates a prob- 


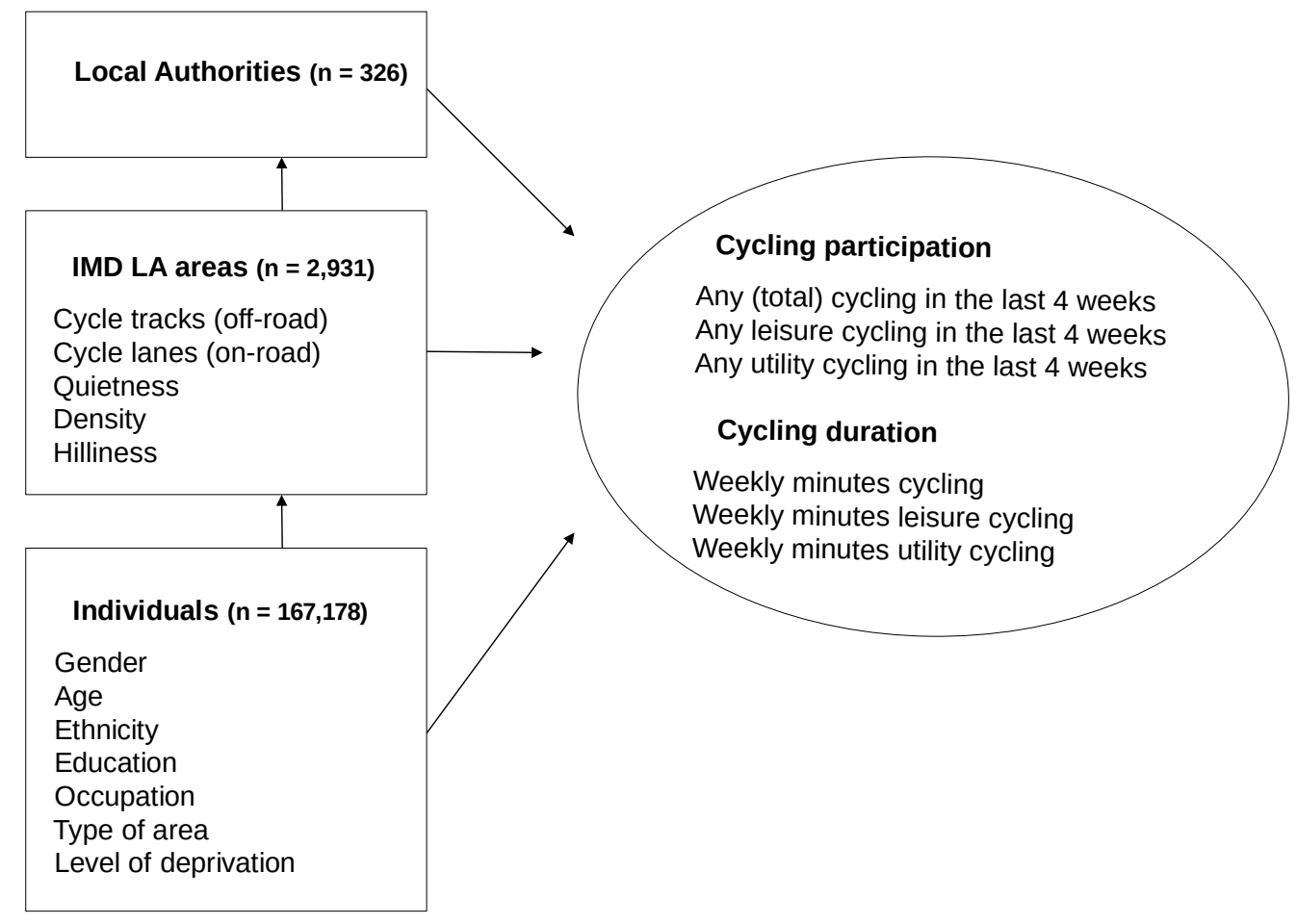

Figure 1: Conceptual models.

lematic amount of collinearity (James et al. 2013). Two independent variables initially included in our data set (vehicle ownership and average commute distance) were excluded for exceeding this value. In the process of selecting the variables, where two factors were strongly correlated; we kept those that were considered socioeconomically more relevant. To simplify and focus on the aims of the study, the models were presented in a table stratified by quintile level of deprivation without showing the rest of the explanatory variables (Table 2). The full results of the models can be seen in Table 3, Table 4, and Table 5 in Appendix A. Final weights (wt_final) provided for the ALS were applied to reduce the bias in survey estimates.

\section{Results}

\subsection{Descriptive results}

On average, in England, 20\% of the population did any (total) cycling in the last 4 weeks, $17 \%$ for leisure, and $8 \%$ for utility. The average weekly time cycling was 181 minutes for those who did any (total) cycling in the last 4 weeks, 140 minutes for those who did any leisure cycling, and 199 minutes for those who did any utility cycling. Whereas leisure cycling is rather evenly geographically distributed (Figure 2 Center), utility cycling (Figure 2 Right) appears more concentrated in specific areas such as Cambridge, Oxford, Isles of Scilly, or Hackney. A higher proportion of leisure cycling does not necessarily correspond with a higher proportion of utility cycling. For example, Local Authorities such as Rushcliffe or Hart, with more than $25 \%$ of leisure cycling, have less than $10 \%$ of utility cycling. In contrast, most of the areas with high utility cycling have also a significant presence of leisure cycling.

Overall, the lower the level of deprivation, the higher the proportion of cycling participation (Figure 3 Left). This trend is clearly observed for leisure cycling (Figure 3 Center). However, utility cycling remains flat across all levels of deprivation (Figure 3 Right). 

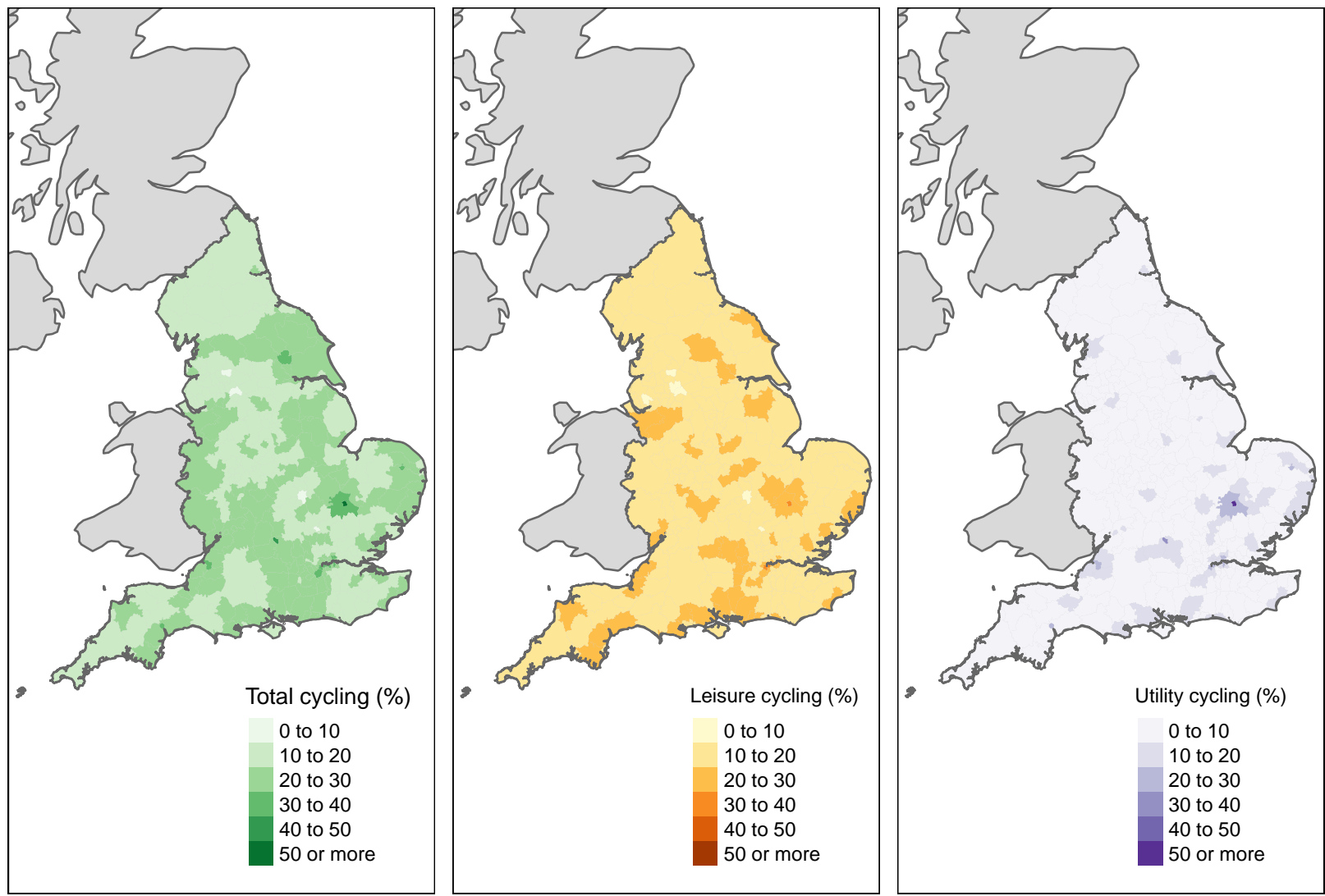

Figure 2: Maps of England illustrating the proportion of people who did any (total) cycling (left), any leisure cycling (center), and any utility cycling (right) in the last 4 weeks.

By contrast, the average cycling duration is slightly higher in more deprived areas than in less deprived areas (Figure 4 Left). This difference is more noticeable for utility cycling, particularly in areas from the first quintile compared to those from the rest of quintiles (Figure 4 Right).

Contrary to our expectations, on average, the more deprived the areas the higher the density of cycling infrastructure. This is the case for both considered types of cycling infrastructure: cycle tracks (off-road) and cycle lanes (on-road) (Figure 5).

Figure 6 shows the area-level variables proportion cycling participation (for total, utility, and leisure cycling), cycle tracks, cycle lanes, quietness, density, and hilliness standardized by quintile level of deprivation. The result is paradoxical. While the proportions of total and leisure cycling, as well as hilliness, follow a positive trend from more to less deprived quintile, the environmental variables referring to the built environment (cycle tracks, cycle lanes, quietness, and density) generally follow the opposite tendency. That is, in areas where the environment is supposedly more suitable for cycling, cycling proportions are lower; whereas in areas where the environment is less cycle-friendly, cycling proportions are higher.

\subsection{Multilevel analyses}

\subsubsection{Associations between level of deprivation and cycling participation}

The multilevel logistic models adjusting for the 'individual' fixed effects (Table 2) show a clear negative association between level of deprivation and total cycling participation: the higher the level of deprivation the lower the likelihood of any cycling participation. This trend is slightly stronger for leisure cycling than for total cycling. For utility cycling, no significant association was found. 


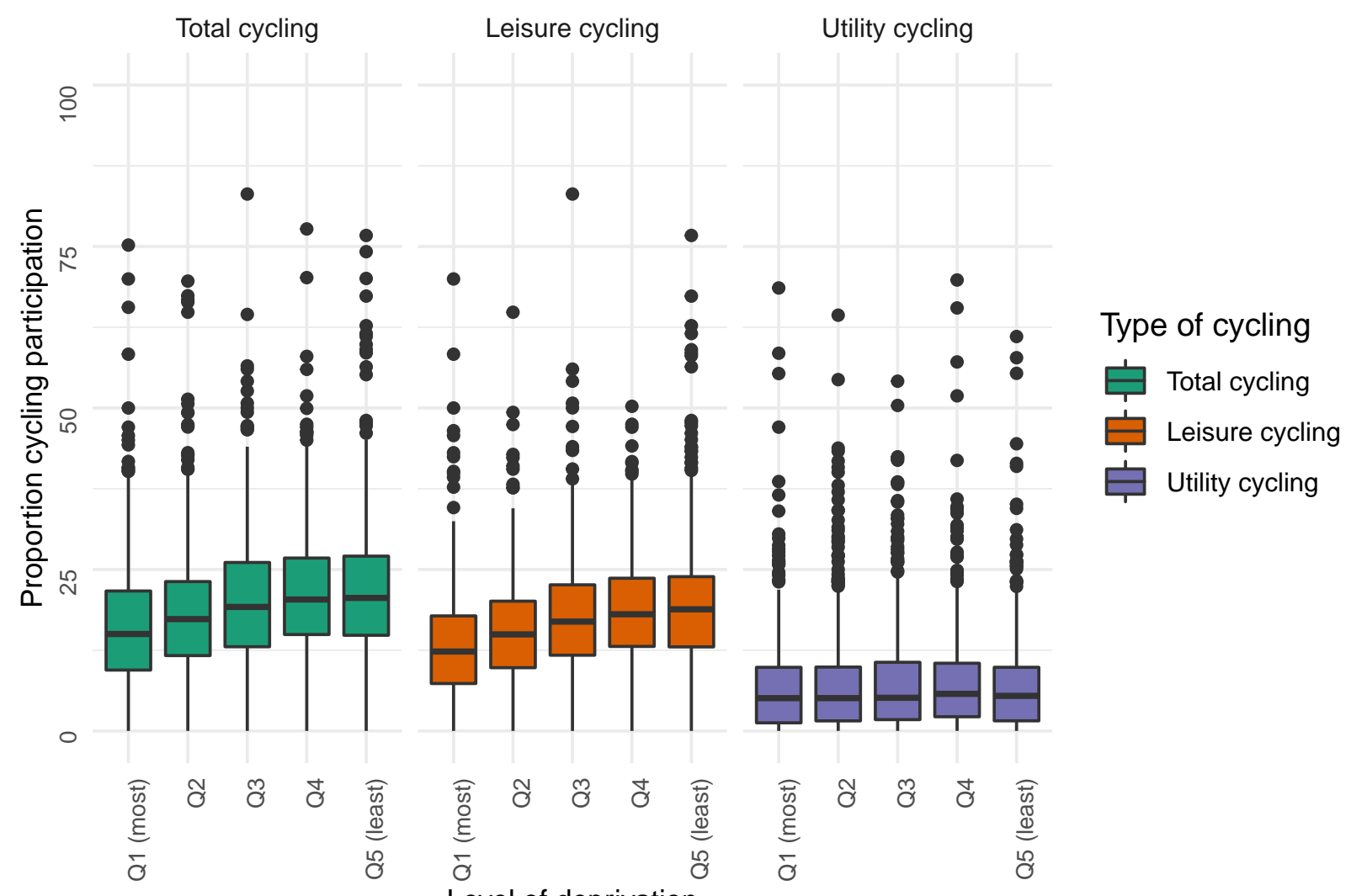

Figure 3: Boxplots of the proportion of people who did any (total) cycling (left), any leisure cycling (center), and any utility cycling (right) in the last 4 weeks by quintile level of deprivation.

When we adjust for the 'individual' and 'area' fixed effects (Table 2), the disparities increase. All else being equal, someone in Q5 is 52\% more likely to have cycled in the last 4 weeks than a similar individual in a comparable environment in Q1. This increase of inequalities in total cycling is mostly caused by the increment of disparities in the Q3, Q4, and Q5 quintiles for utility cycling. This suggests that if the areas in these quintiles (Q3, Q4, and Q5) had the same environmental attributes (in terms of cycle tracks, density, and hilliness) as the areas in Q1, more people that lives in them would cycle for transport. Therefore, we can conclude that the environmental variables found significantly associated with utility cycling participation (i.e., cycle tracks density, population density, and hilliness - see Table 5) contribute to equal utility cycling among the different socioeconomic groups.

\subsubsection{Associations between level of deprivation and cycling duration}

The multilevel gamma models adjusting for 'individual' fixed effects (Table 2) show a positive association between level of deprivation and cycling duration. That is, those who did any cycling in the last 4 weeks living in deprived areas were more likely to cycle longer per week than those who did any cycling in the last 4 weeks living in non-deprived areas. The effect of this association is slightly higher for utility than for leisure cycling.

Adjusting the gamma models for the 'individual' and 'area' fixed effects (Table 2) hardly alter the ORs and significance results. This suggests that the environmental attributes (considered in our models) do not substantially influence the time that people cycle per week. 


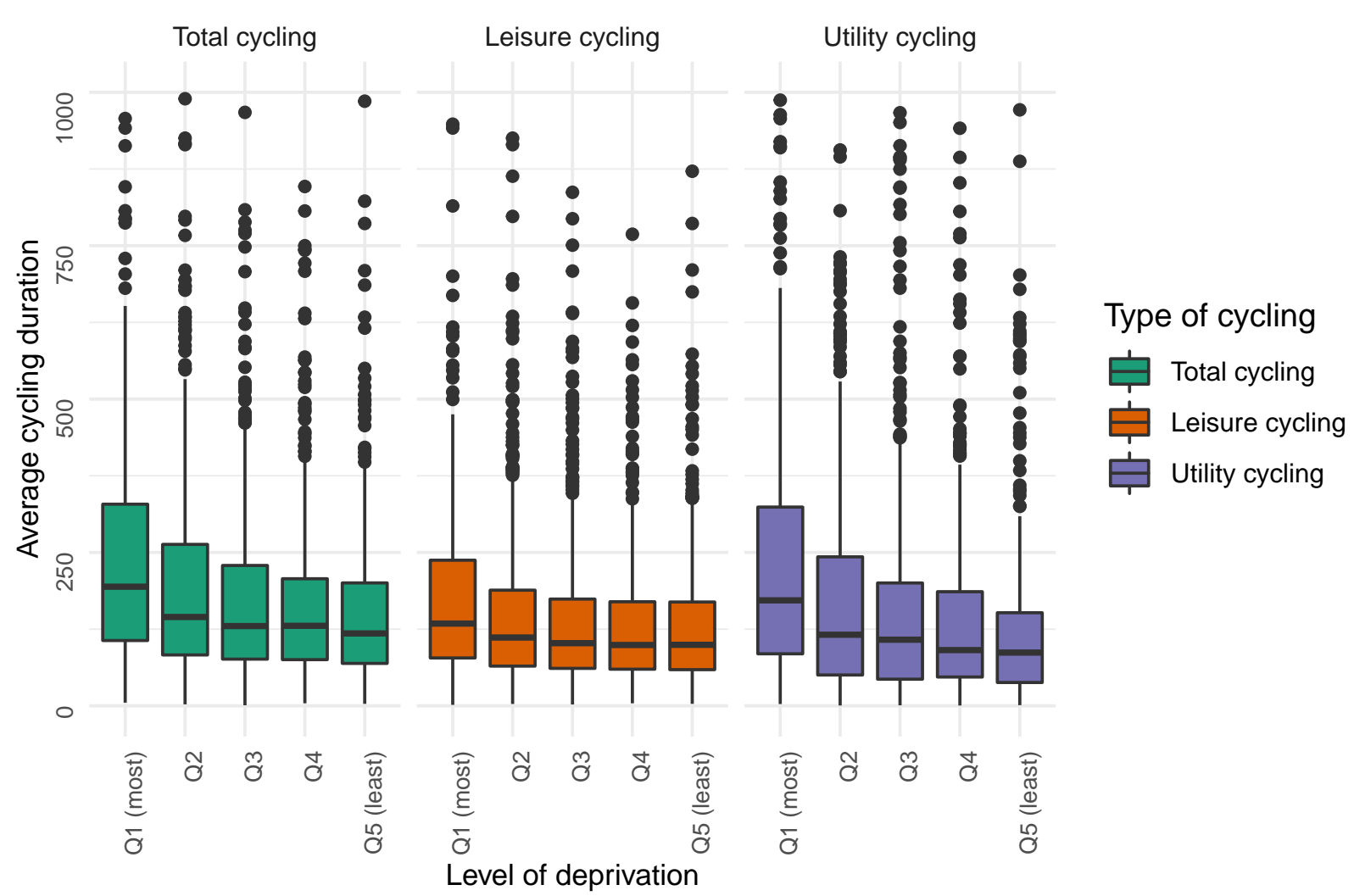

*To improve whiskers visualisation 22 values over 1000 minutes/week were not included

Figure 4: Boxplots of the average cycling duration (in minutes per week) for those who did any (total) cycling (left), any leisure cycling (center), and any utility cycling (right) in the last 4 weeks by quintile level of deprivation.

\section{Discussion}

The first aim of this study was to analyze the extent to which socioeconomic disadvantage in England impacts cycling participation and cycling duration for both leisure cycling and utility cycling. A significant negative relationship between level of deprivation and cycling participation was found for leisure cycling. However, for utility cycling, no significant association was found. Although to the best of our knowledge, no study in the UK has explored the relationship between the level of deprivation and leisure cycling, most research from other countries support our finding concluding that leisure cycling is more common among non-deprived populations than among deprived populations (Bandeira et al. 2017; Heesch et al. 2015; Kamphuis et al. 2008). Previous studies that looked at the relationship between deprivation and utility cycling in England have focused on commuting cycling. (Parkin et al. 2008) found a positive link between low-income areas and commuting cycling. However, (Goodman 2013) found that low-income groups commuted by bicycle slightly more than higher affluent groups. Nevertheless, she pointed out that in the period 2001-2011 the differences had been reduced, and reversed in the highest cycling locations, predicting that future cycling in England and Wales might become increasingly concentrated among affluent groups.

On the contrary, a significant positive relationship between level of deprivation and cycling duration was found, i.e., cyclists living in deprived areas were more likely to cycle longer per week than cyclists living in non-deprived areas. This association was slightly stronger for utility than for leisure cycling. The fact that socioeconomically disadvantaged cyclists tend to have less access to other modes of transport such as cars or public transport might explain this disparity for utility cycling. 


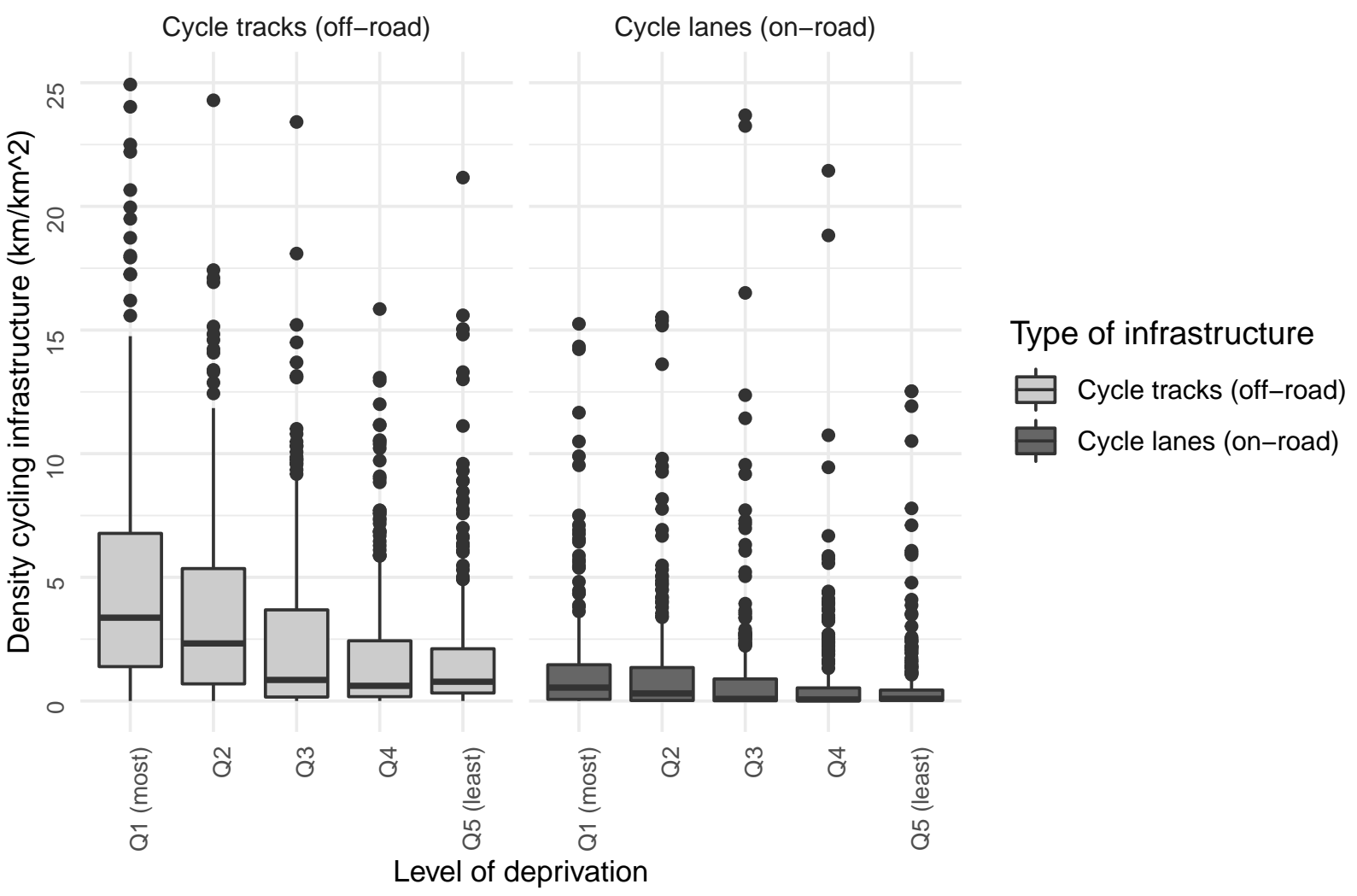

*To improve whiskers visualisation 32 values over $25 \mathrm{~km} / \mathrm{km}^{\wedge} 2$ were not included

Figure 5: Boxplots of the density of cycle tracks (left) and cycle lanes (right) by quintile level of deprivation.

The second aim of the study was to examine whether the socioeconomic inequalities in cycling participation could be explained by inequality in the distribution of environments more prone to cycling. Contrary to our expectations, both the descriptive and the multilevel model analyses indicate that more deprived areas in England are, in general terms, more suitable for cycling and better provided of cycle-friendly infrastructure than less deprived areas. This rejects the hypothesis that the difference in cycling participation per socioeconomic level, demonstrated when addressing the first aim, might be partly explained by inequality in the distribution of cycle-friendly environments (at least in terms of the factors that we analyzed, i.e., infrastructure, quietness, density, and hilliness).

We attribute higher density of cycling infrastructure in deprived areas to the fact that these areas in England (and in most industrialized countries) tend to be located in (or close to) the center of the cities (Margo 1992; Mieszkowski and Mills 1993; Mills and Sende Lubuele 1997), and traditionally city centers have been equipped with more transport infrastructure. However, not in all cities of most industrialized countries, deprived areas are more cycle-friendly. For example, in 22 large US cities was found that access to bike lanes was lower in areas with lower education, higher Hispanic populations, and lower composite SES (Braun et al. 2019). Also in Chicago (Prelog 2015) and Minnesota (Wang and Lindsey 2017), a clear inequity in the distribution of cycling infrastructure was found. Neither in all countries and cities, most deprived populations live in central and dense areas. In Latin American countries, for instance, low-income populations live primarily in distant peripheral areas (Sabatini 2006). This might explain, at least in part, that studies conducted in Latin American countries (Teunissen et al. 2015; Tucker and Manaugh 2018) found disadvantaged areas significantly worse provided of cycling infrastructure than middle and upper-class areas.

The fact that population living in deprived areas despite having better infrastructure and cyclefriendly environment cycle less leads to the conclusion that although spatial determinants are impor- 


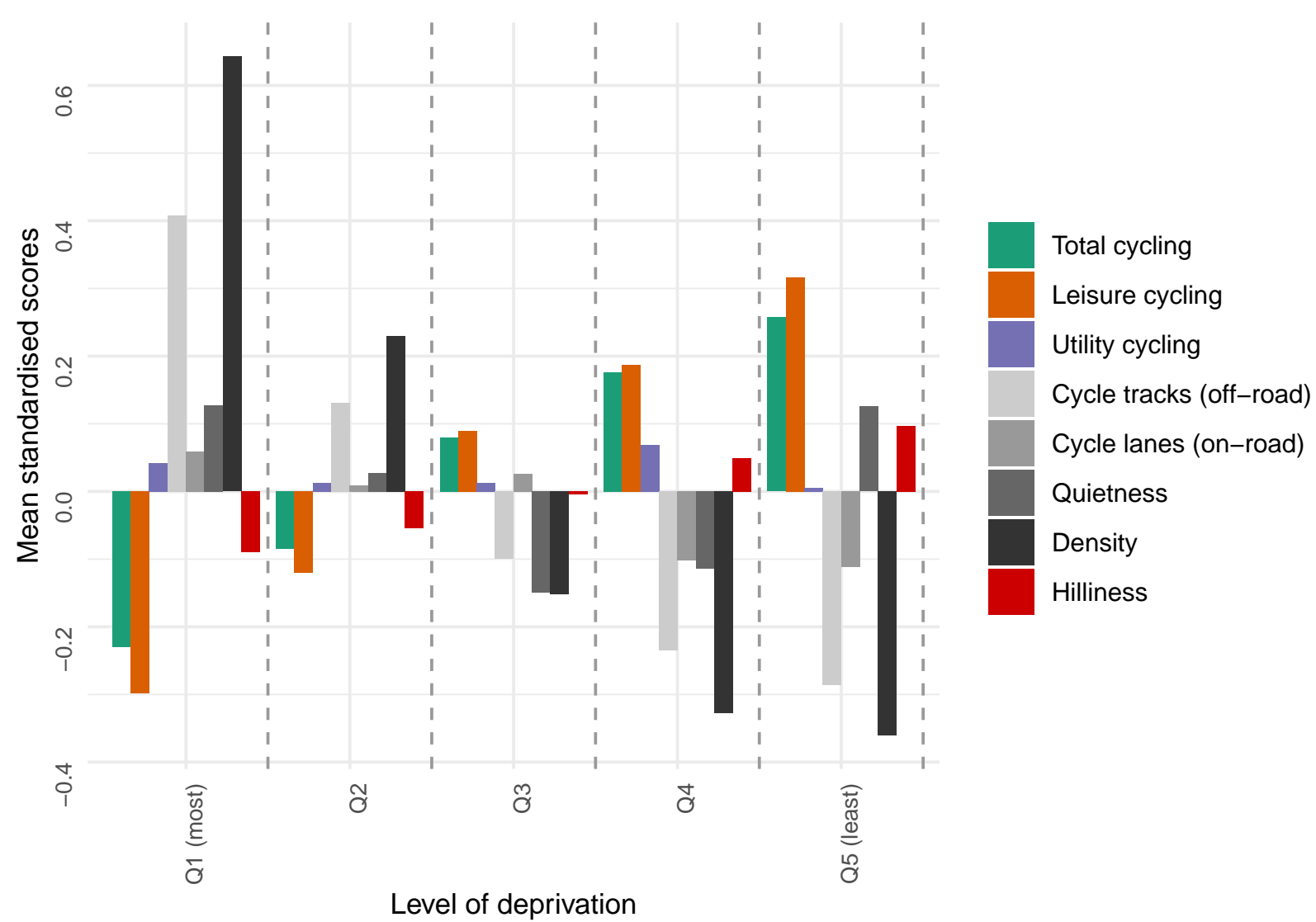

Figure 6: Barplot displaying the mean standardized scores of the area-level variables proportion cycling participation (total, utility, and leisure), cycle tracks, cycle lanes, quietness, density, and hilliness by quintile level of deprivation.

tant for cycling promotion (particularly for utility cycling), social and individual factors must be essential to engage disadvantaged people in cycling.

As full models showed (see Appendix A), non-whites, low-educated, and people with occupations of lower social groups, which are social groups generally linked with socioeconomic disadvantage, were also negatively correlated with cycling. Non-white and low-educated individuals were particularly less likely to cycle for utility (OR 0.43 and OR 0.60 , respectively); whereas, people with occupations of the lower social groups were particularly less likely to cycle for leisure (OR 0.69). According to research, other individual barriers to cycle among disadvantaged populations are: not having a bicycle or gear related, lack of secure storage at home and where they go (McNeil 2011), and cultural aspects such as social stigma of using a bicycle as a mode of transport (Bratman and Jul 2014; Steinbach et al. 2011). Strengths of this study include the use of the nationally representative ALS. The ALS is one of the largest surveys of its kind, with 179,747 valid responses for the period mid-November 2017 to midNovember 2018(Ipsos MORI 2019). The inclusion of both leisure cycling and utility cycling in the analyses is another strength. Most of the studies that previously looked at the relationship between socioeconomic disadvantage and cycling in the UK were focused only on cycling commuting.

Several limitations associated with the input data and our focus on IMD scores as a proxy for disadvantage should be considered when interpreting the results and drawing conclusions. First, the study used cross-sectional data and consequently cannot be used to infer causality: the reasons why people living in disadvantaged areas cycle less than people living in non-disadvantaged areas are still uncertain in the UK and beyond. We suggest that understanding the causal pathways should be a priority of future research into cycling inequalities. Second, the data used from the ALS is self-reported 
Table 2: Associations between level of deprivation (IMD quintiles) and total, leisure, and utility cycling participation, and total, leisure, and utility cycling duration

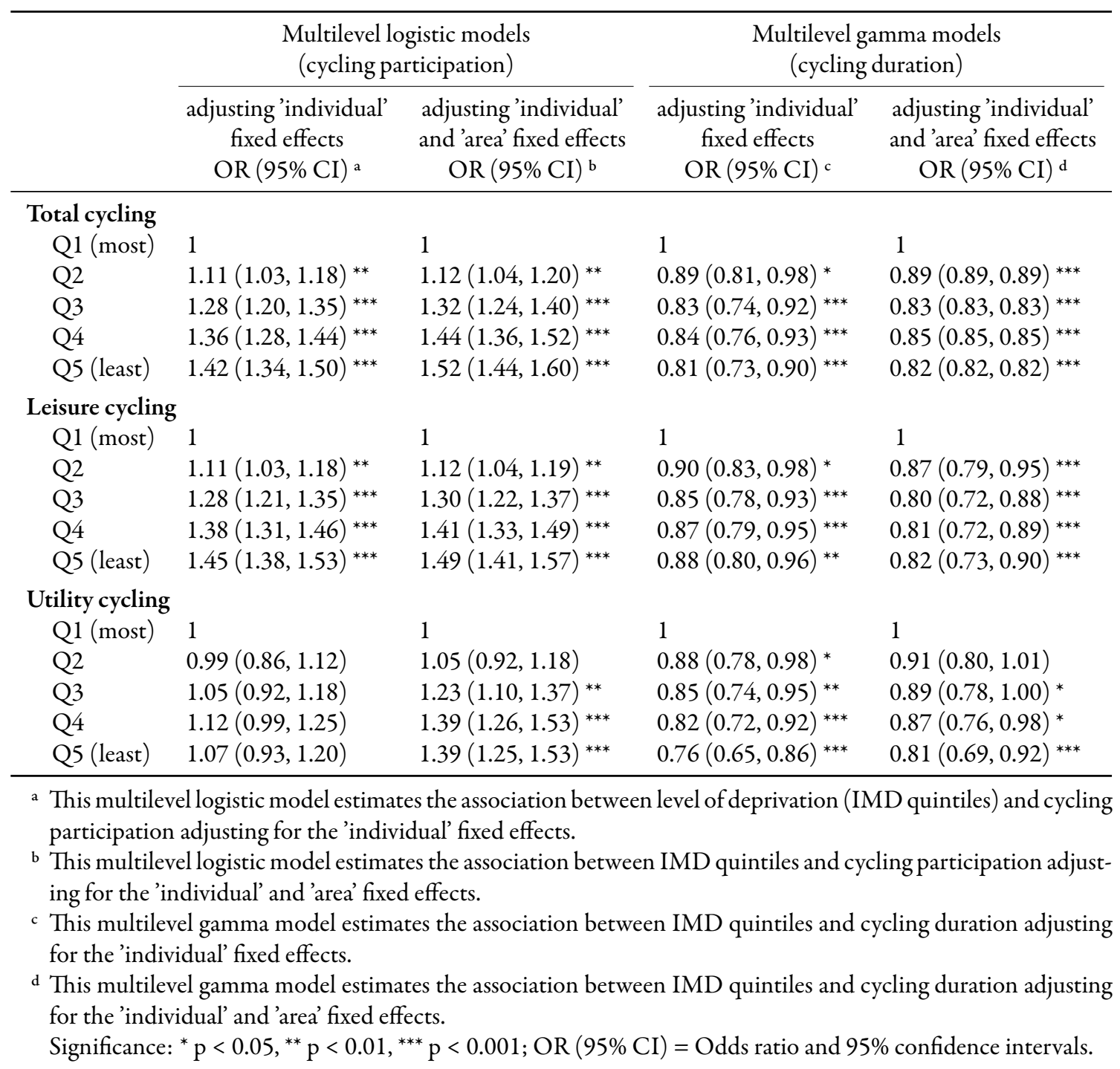

which implies a potential risk of bias assessment. A systematic review (Prince et al. 2008) comparing direct versus self-report measures for assessing physical activity in adults found out that, self-report measures of physical activity were both higher and lower than directly measured levels of physical activity. Third, we did not have access to the residential LSOA of individuals, which is the level at which the IMD is collected. To overcome this limitation, we had to aggregate the LSOAs dataset by IMD decile and Local Authority (LA). This allowed exploring associations between environmental factors and cycling participation per level of deprivation at a sub-local authority level (see section 2.3). Fourth, although most of our data were at the individual-level, the key variable of the analysis, 'level of deprivation', referred to the level of deprivation of the area where respondents lived, but not the level of deprivation of individuals or households. Therefore, among the cycling participation considered of disadvantaged populations, there could be included, for example, cycling participation of affluent young professionals (also known as 'hipsters'), who tend to live in deprived areas and cycle more often than average. This suggests that bicycle use of disadvantaged populations could be even lower than we reported. In the same way, though, cycling participation considered of non-deprived populations could be of disadvantaged populations living in wealthier areas. Fifth, the research did not account for potential confounding variables such as attractiveness/aesthetics, crime, road safety, 
and air quality previously linked with cycling levels (Edwards et al. 2006; Kremers et al. 2012; Mitchell and Dorling 2003; Timms and Tight 2010). These could plausibly affect the likelihood of cycling in ways that are not accounted for in our research. Finally, the variables 'cycle track (off-road)' and 'cycle lane (on-road)' were sourced from the OpenStreetMap (OSM) which is built through crowdsourced volunteered geographic information. This implies the risk that in areas where people contribute more the information may be more detailed and vice-versa, suggesting further avenues for research that use more accurate and systematically collected data on cycling infrastructure.

\section{Conclusions}

This research found that the likelihood of cycling in England is lower among people living in deprived areas than among people living in non-deprived areas. This difference is statistically significant for leisure cycling, but also for utility cycling when controlling for individual and environmental factors. However, cyclists living in deprived areas were found to cycle longer per week than cyclists living in non-deprived areas, particularly for utility cycling. The study also found, contrary to our expectations, that cycling infrastructure supply and levels of cyclability are higher in deprived areas than in nondeprived areas in England. This is attributed to the fact that deprived areas in England tend to be located in city centers, where cycling infrastructure and traffic calm measures have been traditionally more often implemented. The paradox of a lower likelihood of cycling in deprived areas where the environment may be more cycle-friendly suggests that the provision of infrastructure and cyclability alone is not enough to engage more disadvantaged population in cycling.

Interventions to increase access to bicycles (either for ownership and secure storage space) and against the social stigma of cycling among socioeconomically disadvantaged populations should be taken into consideration, as some studies suggest. Even so, further research on barriers to cycling among socioeconomically disadvantaged populations, and how these barriers intersect with other types of disadvantage is required to provide the evidence needed for effective interventions to enabling the benefits of cycling to be available for all.

\section{Acknowledgements}

We would like to thank Sport England (Nathan Cheetham and Helen Price) for providing the ALS dataset used for this study. Thanks also to Professor Kelvyn Jones (University of Bristol) and Andrea Gilardi (University of Milan) for the useful discussions on multilevel modelling. EVT completed this work as part of a Doctorate funded by the Economics and Social Research Council (ES/R501062/1). RPM was supported by a UK Research and Innovation Future Leaders Fellowship (MR/S032525/1). 


\section{Appendix A Models full results}

This appendix shows the full results of the multilevel regression models for total cycling (Table 3), for leisure cycling (Table 4), and for utility cycling (Table 5). 


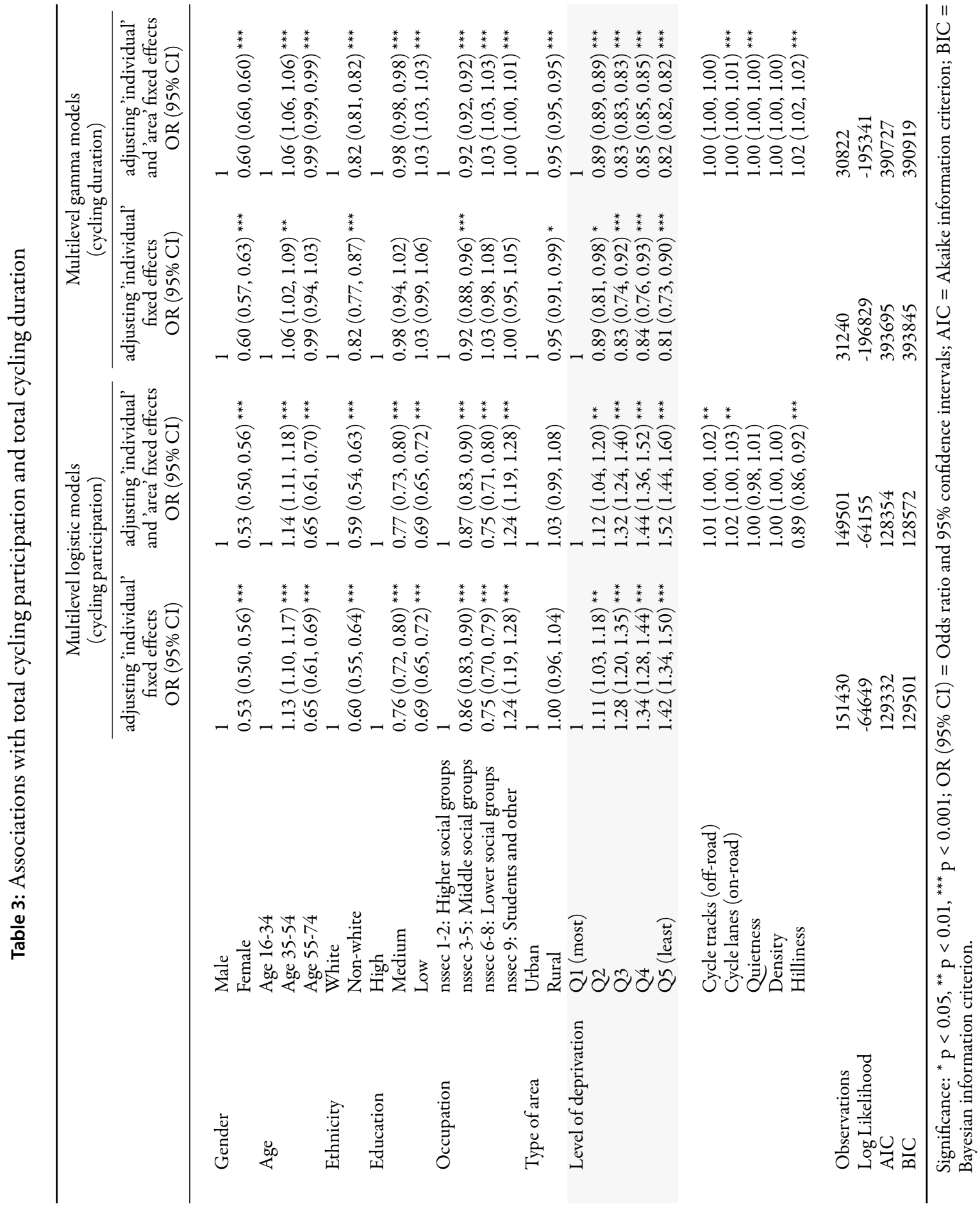




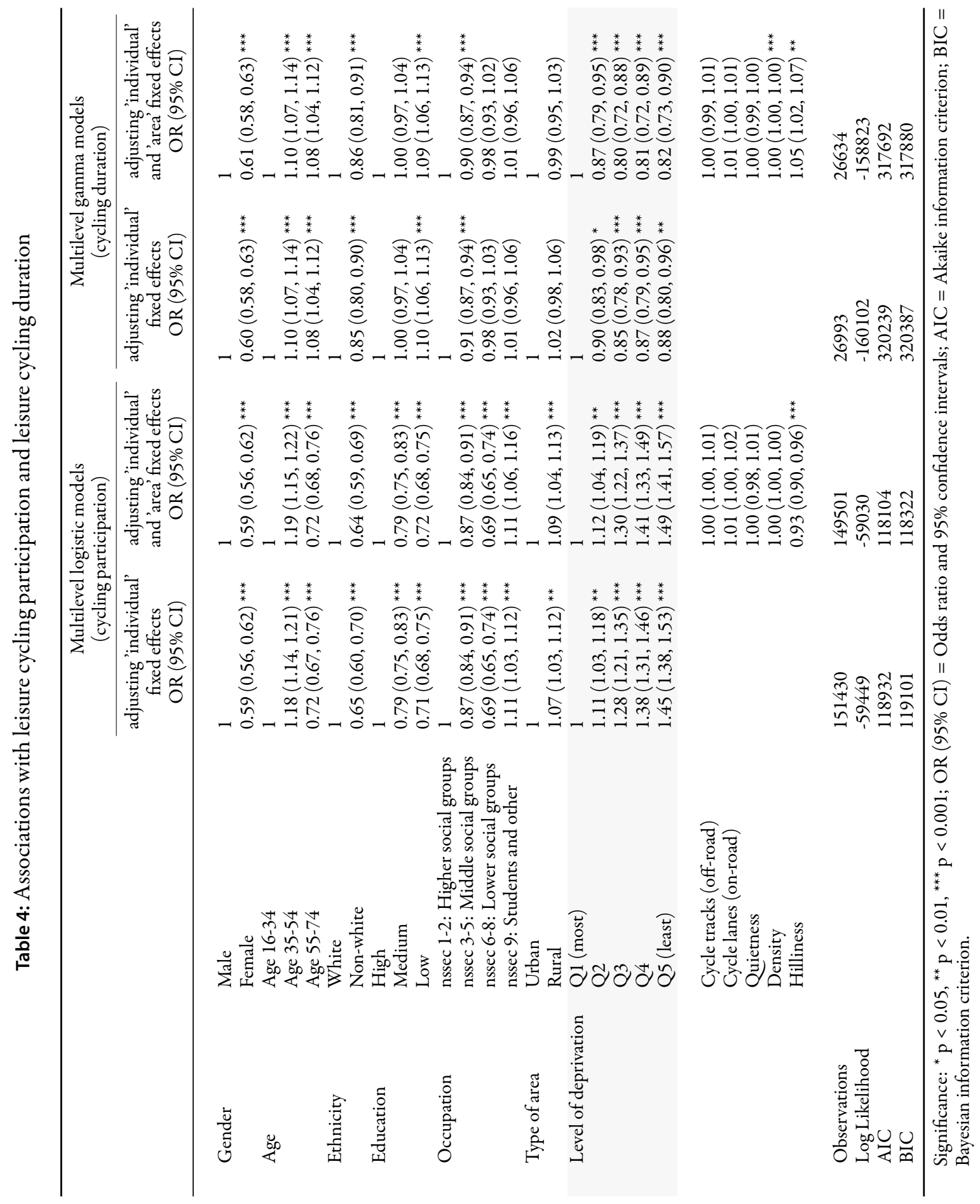




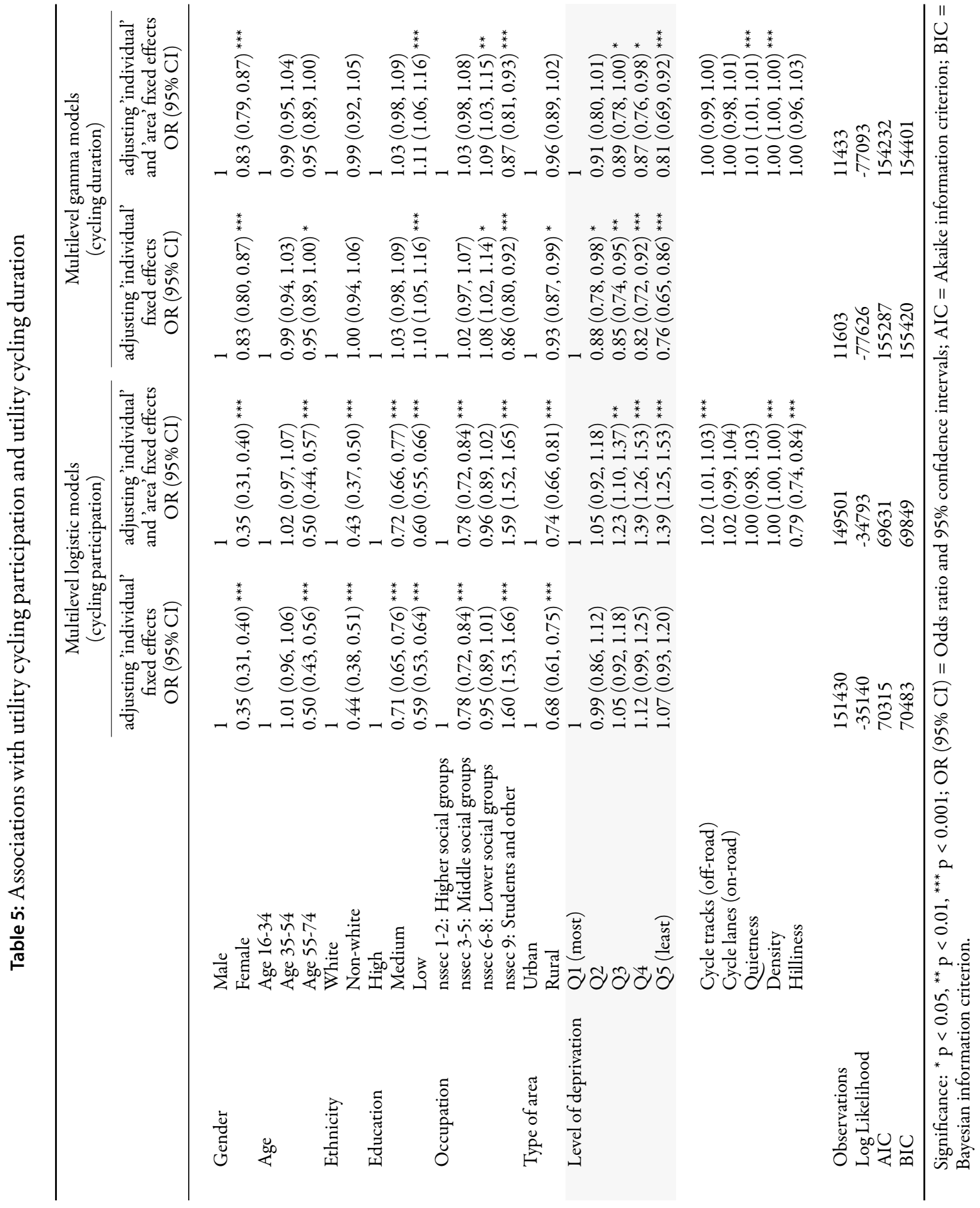




\section{References}

Bandeira, A. d. S., K. S. da Silva, G. F. Del Duca, G. R. Zilch, E. S. A. de Oliveira, M. V. G. de Barros, and M. V. Nahas. 2017. Factors associated with bicycle use for commuting and for leisure among Brazilian workers. Sport Sciences for Health, 13(1):63-68. ISSN 1824-7490, 1825-1234. doi: 10.1007/s11332-017-0350-0. URL http://link.springer.com/10.1007/s11332-017-0350-0.

Bratman, E. and A. J. Jul. 2014. How Low-Income Commuters View Cycling. In The Future of Transportation, p. 4. CITYLAB. URL https://www.citylab.com/transportation/2014/07/ how-low-income-commuters-view-cycling/374390/.

Braun, L. M., D. A. Rodriguez, and P. Gordon-Larsen. 2019. Social (in)equity in access to cycling infrastructure: Cross-sectional associations between bike lanes and area-level sociodemographic characteristics in 22 large US cities. Journal of Transport Geography, 80:102544. ISSN 09666923. doi: 10.1016/j.jtrangeo.2019.102544. URL https://linkinghub.elsevier.com/retrieve/ pii/S096669231830930X.

Brussel, M. and M. Zuidgeest. 2012. Chapter 8 Cycling in Developing Countries: Context, Challenges and Policy Relevant Research. In Cycling and Sustainability. Emerald Group Publishing Limited. ISBN 978-1-78052-298-2.

Clark, J. and A. Curl. 2016. Bicycle and car share schemes as inclusive modes of travel? A socio-spatial analysis in Glasgow, UK. Social Inclusion, 4(3):83. ISSN 2183-2803. doi: 10.17645/si.v4i3.510. URL http://www.cogitatiopress.com/ojs/index.php/socialinclusion/article/view/510.

Cycle Streets. 2020. Journey Planner - plan a cycle journey. URL https://www.cyclestreets.net.

DfCLG. 2015. The English Indices of Deprivation 2015: Research report. p. 94. URL https://www. gov.uk/government/statistics/english-indices-of-deprivation-2015.

DfT. 2017. Cycling and Walking Investment Strategy. p. $38 . \quad$ URL https://assets. publishing.service.gov.uk/government/uploads/system/uploads/attachment_data/file/874708/ cycling-walking-investment-strategy.pdf.

Dill, J. and T. Carr. 2003. Bicycle commuting and facilities in major US cities: If you build them, commuters will use them. Transportation Research Record: Journal of the Transportation Research Board, 1828(1):116-123. ISSN 0361-1981, 2169-4052. doi: 10.3141/1828-14. URL http:// journals.sagepub.com/doi/10.3141/1828-14.

Droomers, M. 2001. Educational level and decreases in leisure time physical activity: Predictors from the longitudinal GLOBE study. Journal of Epidemiology \& Community Health, 55(8):562-568. ISSN 0143005X. doi: 10.1136/jech.55.8.562. URL http://jech.bmj.com/cgi/doi/10.1136/jech. 55.8.562.

Edwards, P., J. Green, I. Roberts, C. Grundy, and K. Lachowycz. 2006. Deprivation and Road Safety in London: A report to the London Road Safety Unit. Technical report, London School of Hygiene and Tropical Medicine.

Fraser, S. D. and K. Lock. 2011. Cycling for transport and public health: A systematic review of the effect of the environment on cycling. European Journal of Public Health, 21(6):738-743. ISSN 1464-360X, 1101-1262. doi: 10.1093/eurpub/ckq145. URL https://academic.oup.com/eurpub/ article-lookup/doi/10.1093/eurpub/ckq145.

Fuller, D. and M. Winters. 2017. Income inequalities in Bike Score and bicycling to work in Canada. Journal of Transport \& Health, 7:264-268. ISSN 22141405. doi: 10.1016/j.jth.2017.09.005. URL https://linkinghub.elsevier.com/retrieve/pii/S2214140517301573.

Garrard, J., C. Rissel, and A. E. Bauman. 2012. Health Benefits of Cycling. In City cycling (Vol. 11). Cambridge, MA: MIT Press.

Giles-Corti, B. 2002. Socioeconomic status differences in recreational physical activity levels and real and perceived access to a supportive physical environment. Preventive Medicine, 35(6):601-611. ISSN 00917435. doi: 10.1006/pmed.2002.1115. URL https://linkinghub.elsevier.com/retrieve/ pii/S0091743502911151. 
Goodman, A. 2013. Walking, cycling and driving to work in the English and Welsh 2011 Census: Trends, socio-economic patterning and relevance to travel behaviour in general. PLoS ONE, 8(8):e71790. ISSN 1932-6203. doi: 10.1371/journal.pone.0071790. URL http://dx.plos.org/10. 1371/journal.pone.0071790.

Goodman, A. and J. Cheshire. 2014. Inequalities in the London bicycle sharing system revisited: Impacts of extending the scheme to poorer areas but then doubling prices. Journal of Transport Geography, 41:272-279. ISSN 09666923. doi: 10.1016/j.jtrangeo.2014.04.004. URL http:// www.sciencedirect.com/science/article/pii/S0966692314000659.

Green, J., R. Steinbach, P. Edwards, and J. Datta. 2010. Cycling in London: A study of social and cultural factors in transport mode choice. Technical Report, LSHTM, London.

Handy, S. L. and Y. Xing. 2011. Factors correlated with bicycle commuting: A study in six small us cities. International Journal of Sustainable Transportation, 5(2):91-110. ISSN 1556-8318, 1556 8334. doi: 10.1080/15568310903514789. URL http://www.tandfonline.com/doi/abs/10.1080/ 15568310903514789 .

Heesch, K. C., B. Giles-Corti, and G. Turrell. 2015. Cycling for transport and recreation: Associations with the socio-economic, natural and built environment. Health \& Place, 36:152-161. ISSN 13538292. doi: 10.1016/j.healthplace.2015.10.004. URL http://linkinghub.elsevier.com/ retrieve/pii/S1353829215001458.

Heinen, E., B. van Wee, and K. Maat. 2010. Commuting by bicycle: An overview of the literature. Transport Reviews, 30(1):59-96. ISSN 01441647. doi: 10.1080/01441640903187001. URL http://www.tandfonline.com/doi/abs/10.1080/01441640903187001.

Ipsos MORI. 2019. Active Lives Survey 2017/2018 Year 3 Technical Report. Technical report, Ipsos MORI Social Research Institute.

James, G., D. Witten, T. Hastie, and R. Tibshirani. 2013. An Introduction to Statistical Learning, volume 103 of Springer Texts in Statistics. New York, NY: Springer New York. ISBN 978-1-46147137-0 978-1-4614-7138-7. doi: 10.1007/978-1-4614-7138-7. URL http://link.springer.com/ 10.1007/978-1-4614-7138-7.

Kamphuis, C. B. M., K. Giskes, A. M. Kavanagh, L. E. Thornton, L. R. Thomas, F. J. van Lenthe, J. P. Mackenbach, and G. Turrell. 2008. Area variation in recreational cycling in Melbourne: A compositional or contextual effect? Journal of Epidemiology \& Community Health, 62(10):890898. ISSN 0143-005X. doi: 10.1136/jech.2007.067116. URL http://jech.bmj.com/cgi/doi/10. 1136/jech.2007.067116.

Kremers, S. P. J., G.-J. de Bruijn, T. L. S. Visscher, D. J. H. Deeg, G. C. F. Thomése, M. Visser, W. van Mechelen, and J. Brug. 2012. Associations between safety from crime, cycling, and obesity in a Dutch elderly population: Results from the Longitudinal Aging Study Amsterdam. Journal of Environmental and Public Health, 2012. ISSN 1687-9805. doi: 10.1155/2012/127857. URL https://www.ncbi.nlm.nih.gov/pmc/articles/PMC3317166/.

Lee, R. E., H. J. Adamus-Leach, K. C. Cheung, E. G. Soltero, Y. Lopez, F. Saavedra, M. Noor, and S. K. Mama. 2012. Researching those who have the most to gain: Focused physical activity promotion in lower socioeconomic populations. Current Cardiovascular Risk Reports, 6(4):355-361. ISSN 1932-9520, 1932-9563. doi: 10.1007/s12170-012-0243-3. URL http://link.springer.com/10. 1007/s12170-012-0243-3.

Lindström, M., B. S. Hanson, and P.-O. Östergren. 2001. Socioeconomic differences in leisure-time physical activity: The role of social participation and social capital in shaping health related behaviour. Social Science \& Medicine, 52(3):441-451. ISSN 02779536. doi: 10.1016/S02779536(00)00153-2. URL https://linkinghub.elsevier.com/retrieve/pii/S0277953600001532.

Lovelace, R., A. Goodman, R. Aldred, N. Berkoff, A. Abbas, and J. Woodcock. 2017. The Propensity to Cycle Tool: An open source online system for sustainable transport planning. Journal of Transport and Land Use, 10(1). ISSN 1938-7849. doi: 10.5198/jtlu.2016.862. URL https://www.jtlu.org/ index.php/jtlu/article/view/862. 
Lynch, J. W., G. A. Kaplan, R. D. Cohen, J. Tuomilehto, and J. T. Salonen. 1996. Do cardiovascular risk factors explain the relation between socioeconomic status, risk of all-cause mortality, cardiovascular mortality, and acute myocardial infarction? American Journal of Epidemiology, 144(10):934-942. ISSN 0002-9262, 1476-6256. doi: 10.1093/oxfordjournals.aje.a008863. URL https://academic. oup.com/aje/article-lookup/doi/10.1093/oxfordjournals.aje.a008863.

Margo, R. A. 1992. Explaining the postwar suburbanization of population in the United States: The role of income. Journal of Urban Economics, 31(3):301-310. ISSN 00941190. doi: 10.1016/00941190(92)90058-S. URL https://linkinghub.elsevier.com/retrieve/pii/009411909290058S.

McNeil, N. 2011. Bikeability and the 20-min neighborhood: How infrastructure and destinations influence bicycle accessibility. Transportation Research Record: Journal of the Transportation Research Board, 2247(1):53-63. ISSN 0361-1981, 2169-4052. doi: 10.3141/2247-07. URL http://journals.sagepub.com/doi/10.3141/2247-07.

Mieszkowski, P. and E. S. Mills. 1993. The causes of metropolitan suburbanization. Journal of Economic Perspectives, 7(3):135-147. ISSN 0895-3309. doi: 10.1257/jep.7.3.135. URL http://pubs.aeaweb. org/doi/10.1257/jep.7.3.135.

Mills, E. S. and L. Sende Lubuele. 1997. Inner Cities. Journal of Economic Literature, Vol. 35, No. 2:727-756. URL https://www.jstor.org/stable/2729791.

Mitchell, G. and D. Dorling. 2003. An environmental justice analysis of British air quality. Environment and Planning A: Economy and Space, 35(5):909-929. ISSN 0308-518X, 1472-3409. doi: 10.1068/a35240. URL http://journals.sagepub.com/doi/10.1068/a35240.

Oja, P., S. Titze, A. Bauman, B. de Geus, P. Krenn, B. Reger-Nash, and T. Kohlberger. 2011. Health benefits of cycling: A systematic review: Cycling and health. Scandinavian Journal of Medicine \& Science in Sports, 21(4):496-509. ISSN 09057188. doi: 10.1111/j.1600-0838.2011.01299.x. URL http://doi.wiley.com/10.1111/j.1600-0838.2011.01299.x.

ONS. 2019. Lower layer Super Output Area population density (National Statistics). URL https://www.ons.gov.uk/peoplepopulationandcommunity/populationandmigration/ populationestimates/datasets/lowersuperoutputareapopulationdensity.

Parkin, J., M. Wardman, and M. Page. 2008. Estimation of the determinants of bicycle mode share for the journey to work using census data. Transportation, 35(1):93-109. ISSN 00494488. doi: 10.1007/s11116-007-9137-5.

Pistoll, C. and A. Goodman. 2014. The link between socioeconomic position, access to cycling infrastructure and cycling participation rates: An ecological study in Melbourne, Australia. Journal of Transport \& Health, 1(4):251-259. ISSN 22141405. doi: 10.1016/j.jth.2014.09.011. URL https://linkinghub.elsevier.com/retrieve/pii/S2214140514000796.

Plaut, P. O. 2005. Non-motorized commuting in the US. Transportation Research Part D: Transport and Environment, 10(5):347-356. ISSN 13619209. doi: 10.1016/j.trd.2005.04.002. URL https: //linkinghub.elsevier.com/retrieve/pii/S1361920905000179.

Prelog, R. 2015. Equity of Access to Bicycle Infrastructure: GIS methods for investigating the equity of access to bike infrastructure. Technical report, The League of American Bicyclists. URL https: //bikeleague.org/sites/default/files/bike_equity_index_final_web.pdf.

Prince, S. A., K. B. Adamo, M. Hamel, J. Hardt, S. Connor Gorber, and M. Tremblay. 2008. A comparison of direct versus self-report measures for assessing physical activity in adults: A systematic review. International Journal of Behavioral Nutrition and Physical Activity, 5(1):56. ISSN 14795868. doi: 10.1186/1479-5868-5-56. URL http://ijbnpa.biomedcentral.com/articles/10.1186/ 1479-5868-5-56.

Pucher, J. and R. Buehler. 2008. Cycling for everyone: Lessons from Europe. Transportation Research Record: Journal of the Transportation Research Board, 2074(1):58-65. ISSN 0361-1981, 21694052. doi: 10.3141/2074-08. URL http://journals.sagepub.com/doi/10.3141/2074-08.

Pucher, J., R. Buehler, D. R. Bassett, and A. L. Dannenberg. 2010. Walking and cycling to health: A comparative analysis of city, state, and international data. American Journal of Public Health, 
100(10):1986-1992. ISSN 00900036. doi: 10.2105/AJPH.2009.189324.

Pucher, J., C. Komanoff, and P. Schimek. 1999. Bicycling renaissance in North America?: Recent trends and alternative policies to promote bicycling. Transportation Research Part A: Policy and Practice, 33(7):625-654. ISSN 0965-8564. doi: https://doi.org/10.1016/S0965-8564(99)000105. URL https://www.sciencedirect.com/science/article/pii/S0965856499000105.

Sabatini, F. 2006. The Social Spatial Segregation in the Cities of Latin America. Technical report, Inter-American Development Bank. URL https://publications.iadb.org/publications/english/ document/The-Social-Spatial-Segregation-in-the-Cities-of-Latin-America.pdf.

Sahlqvist, S. L. and K. C. Heesch. 2012. Characteristics of utility cyclists in Queensland, Australia: An examination of the associations between individual, social, and environmental factors and utility cycling. Journal of Physical Activity and Health, 9(6):818-828. ISSN 1543-3080, 1543-5474. doi: 10.1123/jpah.9.6.818. URL https://journals.humankinetics.com/view/journals/jpah/9/6/ article-p818.xml.

Schwanen, T. and P. L. Mokhtarian. 2005. What affects commute mode choice: Neighborhood physical structure or preferences toward neighborhoods? Journal of Transport Geography, 13(1):83-99. ISSN 09666923. doi: 10.1016/j.jtrangeo.2004.11.001. URL https://linkinghub.elsevier.com/ retrieve/pii/S0966692304000894.

Steinbach, R., J. Green, J. Datta, and P. Edwards. 2011. Cycling and the city: A case study of how gendered, ethnic and class identities can shape healthy transport choices. Social Science \& Medicine, 72(7):1123-1130. ISSN 02779536. doi: 10.1016/j.socscimed.2011.01.033. URL http://linkinghub.elsevier.com/retrieve/pii/S0277953611000785.

Teunissen, T., O. Sarmiento, M. Zuidgeest, and M. Brussel. 2015. Mapping equality in access: The case of Bogotás sustainable transportation initiatives. International Journal of Sustainable Transportation, 9(7):457-467. ISSN 1556-8318, 1556-8334. doi: 10.1080/15568318.2013.808388. URL http://www.tandfonline.com/doi/abs/10.1080/15568318.2013.808388.

Timms, P. and M. Tight. 2010. Aesthetic aspects of walking and cycling. Built Environment, 36(4):487-503. ISSN 02637960. doi: 10.2148/benv.36.4.487. URL http://openurl.ingenta. $\mathrm{com} /$ content $/$ xref?genre $=$ article\&issn $=0263-7960 \&$ volume $=36 \&$ issue $=4 \&$ spage $=487$.

Tucker, B. and K. Manaugh. 2018. Bicycle equity in Brazil: Access to safe cycling routes across neighborhoods in Rio de Janeiro and Curitiba. International Journal of Sustainable Transportation, 12(1):29-38. ISSN 1556-8318, 1556-8334. doi: 10.1080/15568318.2017.1324585. URL https://www.tandfonline.com/doi/full/10.1080/15568318.2017.1324585.

University of Leeds. 2019. Cycling Infrastructure Prioritisation Toolkit (CyIPT). URL https://www. cyipt.bike/.

Vasconcellos, E. A. 2001. Non-motorized modes. In Urban Transport, Sosteinability and Social Equity. The Case for Developing Countries., pp. 115-119. Routledge.

Wang, J. and G. Lindsey. 2017. Equity of bikeway distribution in Minneapolis, Minnesota. Transportation Research Record: Journal of the Transportation Research Board, 2605(1):18-31. ISSN 0361-1981, 2169-4052. doi: 10.3141/2605-02. URL http://journals.sagepub.com/doi/10.3141/ 2605-02.

Wang, Y., C. Chau, W. Ng, and T. Leung. 2016. A review on the effects of physical built environment attributes on enhancing walking and cycling activity levels within residential neighborhoods. Cities, 50:1-15. ISSN 02642751. doi: 10.1016/j.cities.2015.08.004. URL https://linkinghub.elsevier. $\mathrm{com} /$ retrieve/pii/S0264275115001158.

Winters, M., M. Brauer, E. M. Setton, and K. Teschke. 2010. Built environment influences on healthy transportation choices: Bicycling versus driving. Journal of Urban Health, 87(6):969-993. ISSN 1099-3460, 1468-2869. doi: 10.1007/s11524-010-9509-6. URL http://link.springer.com/10. 1007/s11524-010-9509-6.

Winters, M., J. Fischer, T. Nelson, D. Fuller, and D. G. T. Whitehurst. 2018. Equity in spatial access to bicycling infrastructure in mid-sized Canadian cities. Transportation Research 
Record: Journal of the Transportation Research Board, 2672(36):24-32. ISSN 0361-1981, 21694052. doi: 10.1177/0361198118791630. URL http://journals.sagepub.com/doi/10.1177/ 0361198118791630.

WYCA. 2019. City Connect: Bradford Leeds Cycle Superhighway. URL https://www. cyclecityconnect.co.uk/our-routes/bradford-leeds-cycle-superhighway/. 